\title{
ADEQUAÇÃO DA ESCÓRIA DA METALURGIA SECUNDÁRIA DO AÇO SILÍCIO GOAT (GRÃO ORIENTADO DE ALTA TEMPERATURA) PRODUZIDO NA APERAM SOUTH AMERICA*
}

\author{
Janeir Ribeiro Dutra ${ }^{1}$ \\ Hélcio de Araújo Quintão² \\ Hélio Braz Loss ${ }^{3}$ \\ Luiz Fernando Andrade de Castro ${ }^{4}$ \\ Pedro José Nolasco Sobrinho ${ }^{5}$ \\ Douglas Vinicius Ferreira De Castro ${ }^{6}$
}

Resumo

Os aços siliciosos de grão orientado (GO) e de grão não orientado (GNO) são aços ligados ao silício para aplicações elétricas. O aço silício de grão orientado possui as propriedades magnéticas otimizadas na direção de laminação, enquanto o de grão não orientado apresenta boas propriedades em qualquer direção. $\mathrm{O}$ aço elétrico de grão orientado tem como principais características as excelentes propriedades magnéticas, desenvolvidas especialmente para a redução das perdas magnéticas e aumento da eficiência de máquinas elétricas. Durante 0 processo de elaboração do aço o principal desafio é o controle de elementos como alumínio, titânio e enxofre, elementos estes provenientes da carga metálica (sucata e gusa) e adições de ligas na panela. Para este controle ser eficaz a estabilidade da composição química da escória na metalurgia secundária é de fundamental importância. O fluxo produtivo do aço GOAT na metalurgia secundária inicia-se no processo VOD(Vaccum Oxygen Decarburization) com término no forno panela. Este trabalho promoveu a adequação da escória da metalurgia secundária do aço GO através da: i. revisão do padrão de consumo de fundentes, mediante estudo de balanço de massa; ii. desenvolvimento de escória sintética para ajustar finamente a basicidade da escória. Os estudos de balanço de massa apontaram que em determinadas situações havia a necessidade da correção da escória para aquecimento no forno panela; iii. implementação de amostragem de escória ao final do processo VOD para correção da basicidade de escória para aquecimento no forno panela; iv. criação de modelo para correção da basicidade da escória. Após a implementação do projeto o controle da escória no forno panela ficou mais efetivo promovendo: i. redução dos teores finais de alumínio e titânio ao final do processo de elaboração no forno panela; ii.possibilidade de correção da quantidade de escória para aquecimento no forno panela sem comprometer a basicidade de escória requerida no processo; iii. atendimento a faixa otimizada do aço GOAT (M3, maior qualidade) passou de $33 \%$ para $65 \%$; iv. redução do desgaste de panelas na elaboração do aço GOAT na metalurgia secundária; v. redução do risco de sucatamento por fora de faixa em alumínio e titânio do aço GOAT na aciaria que representou nos últimos 4 anos uma perda ao processo superior a $R \$ 1,2$ milhão; vi. estabilização da basicidade binária da escória final do Forno Panela dentro da faixa desejável.

Palavras-chave: Aços elétricos, refino secundário e basicidade.

\section{SLAG ADEQUACY OF THE SECONDARY METALLURGY OF THE SILICON STEEL HT- OG (HIGH TEMPERATURE ORIENTED GRAIN) AT APERAM SOUTH AMERICA \\ Abstract}

Grain-oriented and non-oriented grain silicon steels are steels for electrical applications. Grain oriented silicon steel has optimized magnetic properties in only one direction; while grain oriented silicon steel has good magnetic properties in any direction. During the steelmaking process the main challenge is the control of elements such as aluminum, titanium and sulfur. These elements come from the metal load (scrap and pig iron) and additions of alloys in the ladle. For this control to be effective the stability of the chemical composition of the slag in the secondary metallurgy is fundamental and very important. After the implementation of this project the control of the slag in the ladle furnace became more effective promoting: i) reduction of the final contents of aluminum and titanium in the GO steel; ii)possibility of correcting of the amount of slag for heating in the ladle furnace without compromising the basicity in the process; iii) increase from $33 \%$ to $65 \%$ in the production of steel with high quality(M3); iv) 
reduction of the refractory wear of ladles; v) reduction of the risk of out-of-range GOAT steel in aluminum and titanium content in the melt shop which represented in the last 4 years a cost of about US $\$ 400,000.00$ in the production of the GO steel; and vi) the stabilization of the basicity of the slag in the ladle furnace within the desirable range.

Keywords: Grain oriented steel, secondary refining, basicity.

1 Engenheiro de Materiais, Mestrando do programa de Pós-graduação do Depto. de Engenharia Metalúrgica e de Materiais da UFMG.

2 Engenheiro Metalurgista. M.Sc. Consultor da APERAM.

3 Engenheiro Metalurgista. M.Sc. Gerente de Aciaria.

4 Prof. Dr. Depto. de Engenharia Metalúrgica e de Materiais da UFMG.

5 Engenheiro Metalurgista. Pós-doutor. Doutor. M.Sc. Eng. Metalurgista, Gerente Técnico do CPDI Grupo Vamtec.

6 Engenheiro Metalurgista. Metalurgista de Processo APERAM. 


\section{INTRODUÇÃO}

Aços siliciosos de grão orientado, GO, são aços contendo em torno de $3 \%$ de silício e baixíssimos teores de residuais utilizados na confecção de equipamentos elétricos. Tem como características: propriedades magnéticas fortemente anisotrópicas, baixos valores de perda magnética no núcleo e alta indução magnética. A perda magnética típica é fator de comparação entre empresas e reflete o avanço tecnológico e o controle do processo de cada produtor. Existem diferentes tecnologias de produção dos aços de grão orientados e a tecnologia atual de produção do aço grão orientado na Aperam é a desenvolvida na empresa Armco (GOAT - Alta Temperatura de reaquecimento de placas) em 1934.

É crescente a demanda por aços para fins elétricos com propriedades magnéticas cada vez melhor, levando os produtores a buscarem processos de refino cada vez mais precisos. As propriedades magnéticas do produto final são atribuídas a combinação de todas as etapas dos processos de fabricação. Neste aspecto a aciaria é uma das partes essenciais na produção deste aço, através da garantia das restritas faixas de composição química.

A produção do aço GO é um grande desafio para a aciaria devido ao alto nível de complexidade tecnológica envolvida na elaboração deste aço exigindo um rigoroso controle das várias variáveis envolvidas em faixas muito estreitas, além de constante capacitação do pessoal envolvido na produção. Um desses controles na metalurgia secundária é a basicidade binária $\left(\mathrm{CaO} / \mathrm{SiO}_{2}\right)$ que deve situar-se entre 0,70 e 0,90 e, ao mesmo tempo, devem também ser mantidos em menor patamar possível no aço os contaminantes cálcio(Ca), alumínio(Al), titânio(Ti) e fósforo(P).

Devido a necessidade de maior estabilidade na composição química da escória na metalurgia secundária do aço GOAT (Alta Temperatura de reaquecimento de placas), este trabalho visa um estudo em conjunto com a empresa Vamtec, realizando a revisão do processo formação da escória na metalurgia secundária e o desenvolvimento de uma nova escória sintética para correção da escória durante o processo de elaboração.

\section{2 - DESENVOLVIMENTO}

Para atender as excelentes propriedades magnéticas na direção de laminação, o aço de grão orientado requer processos tecnológicos complexos com alto controle durante sua elaboração na aciaria. Elementos como carbono, manganês e enxofre, possuem faixas restritas e o residual de contaminantes como alumínio, titânio e fósforo deve ser os mais baixo possível. Durante processo de elaboração (Figura 1), o principal desafio é o controle de elementos como alumínio, titânio e enxofre, elementos estes provenientes da carga metálica (sucata e gusa) e adições de ligas na panela. Sendo necessário um rigoroso controle das matérias primas utilizadas no processo de fabricação. Outro ponto importante é que durante o vazamento no convertedor MRP-L a passagem de escória pelo furo de corrida (Figura 2) deve ser evitada ao máximo, para minimizar a incorporação destes elementos durante o processo de desoxidação do aço com ligas de silício. 


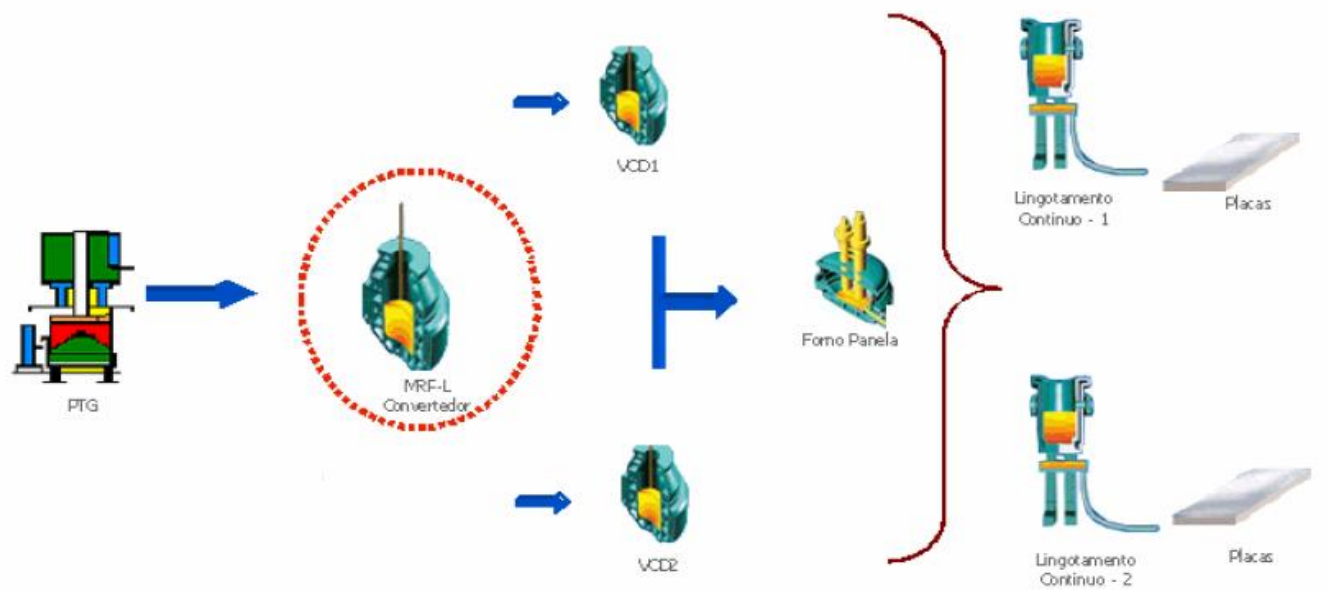

Figura 1 - Fluxograma elaboração aço GO na Aciaria da APERAM

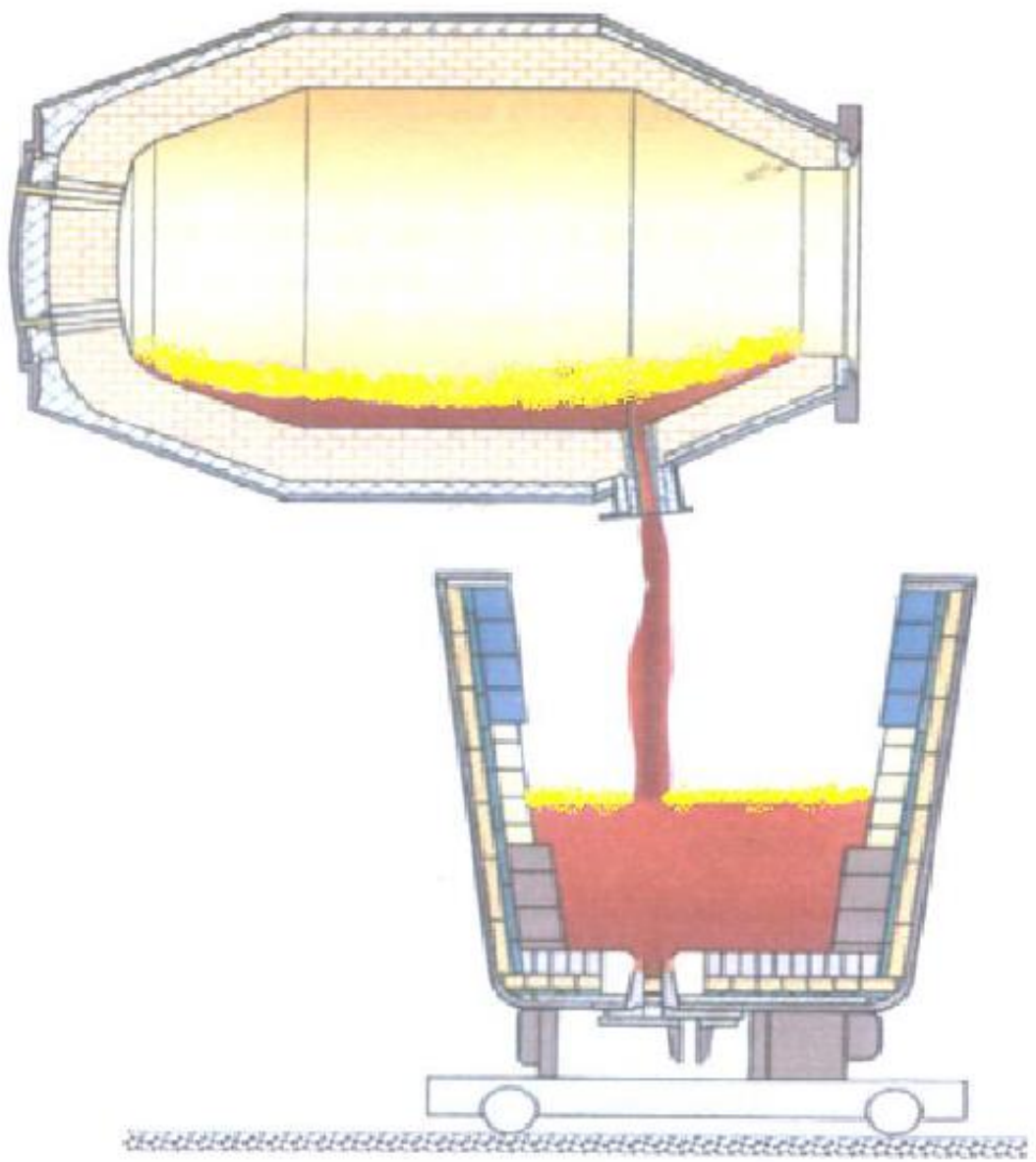

Figura 2 - Figura ilustrativa do vazamento do aço do convertedor para panela O controle dos residuais de alumínio e titânio no refino secundário é eficaz na faixa de basicidade situada entre 0,70 e 0,90.

A basicidade é uma ferramenta largamente utilizada pelos aciaristas para se avaliar a extensão das reações químicas que ocorrem durante o processo de refino do aço. A escória no estado líquido pode ser considerada uma solução iônica. 
A formação dos óxidos básicos envolve a transferência de elétrons do metal para o oxigênio para formar cátions de metal e ânions oxigênio, os quais são ligados no óxido por forças eletrostáticas. As cargas positivas dos cátions são rodeadas pelas cargas negativas dos ânions, e vice-versa, formando uma estrutura de cristal simples.

As formas encontradas para se avaliar o fenômeno que envolve a basicidade de uma escória e seu processo de dissolução variaram em função da evolução do estudo de seu comportamento físico-químico. As mais simples em concepção, porém de alta praticidade, são as relações que envolvem o percentual em massa dos óxidos básicos pelos ácidos. Para o cálculo da basicidade binária $\left(B_{b}\right)$ de uma escória, usa-se a seguinte relação:

$$
B_{b}=\frac{\% \mathrm{CaO}}{\% \mathrm{SiO}_{2}}
$$

A basicidade também pode ser definida como sendo:

$$
B_{t}=\frac{\%(\mathrm{CaO}+\mathrm{MgO})}{\%\left(\mathrm{SiO}_{2}\right)}
$$

Esta relação é conhecida como basicidade ternária $\left(B_{t}\right)$.

Na evolução do cálculo da basicidade foi feita a introdução de dois importantes óxidos:

- $\mathrm{MgO}$ (óxido básico), que é geralmente encontrado no revestimento do refratário;

- $\mathrm{Al}_{2} \mathrm{O}_{3}$, que é um óxido de caráter anfótero, aqui considerado como ácido, podendo ser proveniente do refratário ou na forma de produto da desoxidação.

Assim, a relação para o cálculo da chamada basicidade quaternária $\left(B_{q}\right)$ é:

$$
B_{q}=\frac{\%(\mathrm{CaO}+\mathrm{MgO})}{\%\left(\mathrm{SiO}_{2}+\mathrm{Al}_{2} \mathrm{O}_{3}\right)}
$$

Porém, uma deficiência encontrada nestes tipos de relações é que elas envolvem decisões arbitrárias quanto à natureza ácida ou básica de um óxido. Para os casos em que ocorre a adição de fluorita na formação de escória, ou com a presença de óxidos de caráter anfótero, como $\circ \mathrm{Al}_{2} \mathrm{O}_{3}$ e o $\mathrm{TiO}_{2}$, as relações acima não exprimem a realidade.

Buscando suprir estes problemas surgiu o conceito de basicidade ótica. Neste caso, a basicidade é enfocada em termos da capacidade de doação de elétrons. A palavra ótica deriva da possibilidade de se medir a basicidade da escória espectroscopicamente.

Após uma série de ensaios foi determinado que a basicidade ótica de um óxido $(\Lambda)$ é função da eletronegatividade de Pauling $(\mathrm{X})$ :

$$
\frac{1}{\Lambda}=1,36 \cdot(X-0,26)
$$


Do ponto de vista termodinâmico, pode-se verificar que a dissolução de elementos da escória para o metal é favorecida por basicidades binárias acima de 1,0 e em menor valor de viscosidade da escória.

Escórias com valores de basicidades inferiores a 1 são mais agressivas ao revestimento refratário da panela e exigem maior controle de sua composição química. O sistema busca restabelecer o equilíbrio com óxidos básicos e poderá haver um acentuado desgaste refratário na linha de escória, caso a escória da panela não esteja balanceada adequadamente.

A escória da metalurgia secundária do GOAT é composta pelas seguintes parcelas:

- Escória remanescente de panelas do fluxo produtivo;

- Escória passante do furo de corrida do convertedor;

- Adição de escória sintética (Vamflux RGO SI);

- Adição de fundentes (Óxido de magnésio);

- Óxidos formados durante processo de desoxidação do aço.

Devido variações normais de processo, tais como: Quantidade de escória remanescente na panela, vida do furo de corrida do MRPL, habilidade do operador ao vazar a corrida, dentre outras, observa-se que em determinados casos a contribuição destas parcelas não são satisfatórias para obtenção da basicidade binária requerida para o processo, ficando o processo vulnerável para incorporação de contaminantes como alumínio e titânio. Foram calculados os seguintes cenários:

- Balanço de massa para panelas provenientes do fluxo dos aços GNO;

- Balanço de massa para panelas provenientes do fluxo dos aços GO com furo novo;

- Balanço de massa para panelas provenientes do fluxo dos aços GO com furo desgastado;

- Balanço de massa para panelas novas.

Outros cenários são possíveis de acontecer e afetam diretamente no resultado da basicidade binária da escória, por exemplo, a passagem excessiva de escória durante o vazamento do forno, com a necessidade de raspagem de toda a escória após o vazamento da corrida.

Para o processo de aquecimento no forno panela é necessário a formação de no mínimo $10 \mathrm{~cm}$ de escória para proteção do arco elétrico (Figura 3) e redução da incorporação de carbono no banho via eletrodo de grafite (baixa carburação). Para completar o volume mínimo de escória necessário ao processo do forno panela, é necessário um balanceamento correto da escória para evitar o desgaste excessivo das panelas e incorporação de alumínio e titânio, podendo levar até ao sucateamento da corrida. 


\section{Modelo Cálculo Escória GO}

Peso Placa (kg)

84000

Rendimento Si:

$93,80 \%$

Teor Si placa:

$3,10 \%$

Escória Passante MRPL (cm):

1,0

Escória Processo (cm):

1,0

Composição de química (\%)

\begin{tabular}{lcccc}
\hline Material & $\mathrm{Peso}(\mathrm{t})$ & $\mathrm{CaO}$ & $\mathrm{SiO}_{2}$ & $\mathrm{MgO}$ \\
\hline \hline Escória Sintética & 650 & 59,00 & 16,00 & 6,00 \\
MgO Ibar & 200 & 0,50 & 7,49 & 81,55 \\
Escória Passante MRP & 150 & 41,34 & 13,16 & 10,82 \\
Escória Processo & 150 & 30,48 & 36,45 & 20,38 \\
\hline
\end{tabular}

Basicidade Escória $\left(\mathrm{CaO} / \mathrm{SiO}_{2}\right)$ :

\section{0,88}

Total escória $(\mathrm{kg})$

Altura escória panela $(\mathrm{cm})$

MgO Calculado:

\section{$17,06 \%$}

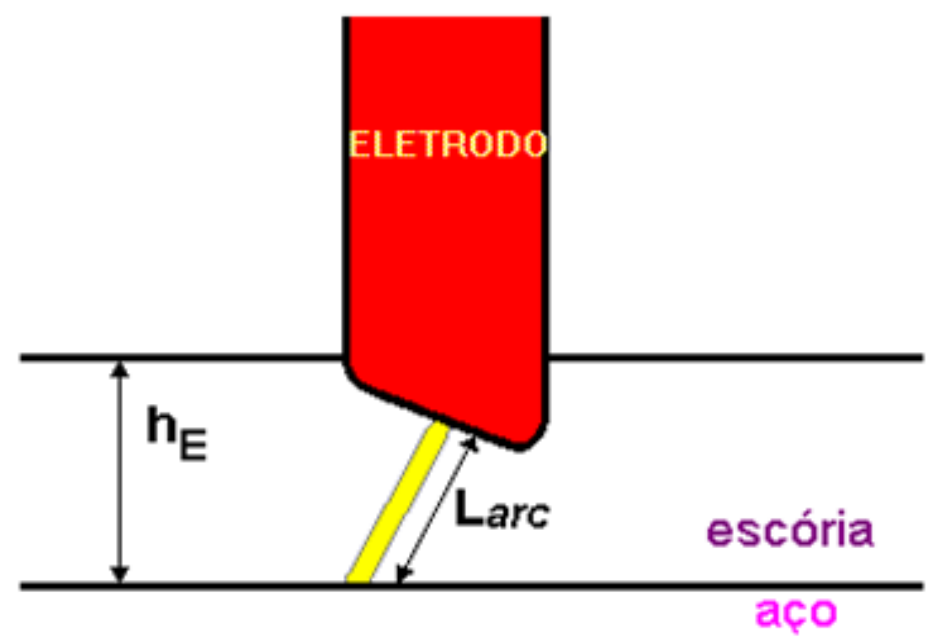

Figura 3 - Desenho esquemático da altura de escória necessária para aquecimento em Forno Panela 
Mediante a vulnerabilidade existente no processo, foram realizados estudos de alternativas junto ao fornecedor de escória sintética para correção da composição da escória durante elaboração do aço na metalurgia secundária. Foi desenvolvida a escória sintética VAMFLUX 4005 para uso na aciaria objetivando o ajuste fino da basicidade binária da escória da panela. O desenvolvimento do produto foi realizado no Centro de Pesquisa, Desenvolvimento e Inovação - CPDI do fornecedor da escória sintética situado na cidade de Timóteo (MG) com seleções de matérias primas adequadas para o desenvolvimento do produto.

Em função do ajuste de basicidade necessário da escória da panela para que fosse mantida entre $0,70-0,90$, foi desenvolvido um programa simulador pela equipe técnica do fornecedor da escória sintética para previsibilidade da composição química da escória final do forno panela.

Este programa consegue prever a basicidade da escória na panela a partir dos dados do processo fornecidos pela APERAM. Este programa possibilitou a construção de uma tabela para orientar a quantidade de VAMFLUX a ser adicionado na panela em função da basicidade da escória da panela no VOD (Vaccum Oxygen Decarburization) e a basicidade que se pretende obter na prática durante aquecimento no Forno Panela. A Tabela 1 apresenta estes valores:

Tabela 1 - Relação entre a basicidade da escória na panela durante a produção do aço RGO e a quantidade necessária de VAMFLUX 4005 para o ajuste fino da basicidade.

\begin{tabular}{|c|c|}
\hline $\begin{array}{c}\text { Basicidade da escória da } \\
\text { panela no VOD }\end{array}$ & $\begin{array}{c}\text { Quantidade de VAMFLUX 4005 a } \\
\text { adicionar na panela(kg) }\end{array}$ \\
\hline 1,20 & 300 \\
\hline 1,10 & 225 \\
\hline 1,00 & 150 \\
\hline 0,95 & 120 \\
\hline 0,90 & 75 \\
\hline
\end{tabular}

Os testes iniciais foram feitos em mar/16 mediante simulado da Tabela 1. Para efetividade da correção da basicidade da escória foi padronizado a realização de amostra de escória ao final do processo do VOD, para que a correção da escória ocorresse antes do início do aquecimento do Forno Panela. Com base nos resultados obtidos na campanha de mar/16, nova análise foi realizada da composição do produto onde se confirmou a formulação inicial e foi dado prosseguimento a utilização do produto na aciaria nas campanhas seguintes de produção do aço GOAT.

Também foi solicitada a disponibilidade da escória sintética VAMFLUX RGO SI em pacotes de $15 \mathrm{~kg}$ para correção da basicidade binária de escória com valores inferiores a 0,75 mediante Tabela 2.

Tabela 2 - Relação entre a basicidade da escória na panela durante a produção do aço GOAT e a quantidade necessária de VAMFLUX RGO SI para o ajuste fino da basicidade. 


\begin{tabular}{|c|c|}
\hline $\begin{array}{c}\text { Basicidade da escória da } \\
\text { panela no VOD }\end{array}$ & $\begin{array}{c}\text { Quantidade de VAMFLUX RGO } \\
\text { Sl a adicionar na panela }(\mathbf{k g})\end{array}$ \\
\hline 0,55 & 300 \\
\hline 0,60 & 250 \\
\hline 0,65 & 150 \\
\hline 0,70 & 100 \\
\hline
\end{tabular}

Outra vantagem com a disponibilidade dos produtos VAMFLUX RGO SI e VAMFLUX 4005 em pacotes de $15 \mathrm{~kg}$ foi a possibilidade da correção da altura de escória necessária para aquecimento no forno panela com as adições realizadas na proporção 2:1. Nesta relação, a escória adicional possui basicidade de 0,80 , não comprometendo a composição química final da escória.

\section{3 - RESULTADOS E DISCUSSÃO}

\section{1 - Considerações termodinâmicas da escória da panela em relação à dessulfuração do aço GOAT}

O aço GOAT é um aço que possui a necessidade do controle rigoroso do elemento enxofre(S) presente na liga durante a metalurgia da panela. $O$ teor deste elemento deve atender valores tipicamente mais elevados em comparação com outros tipos de aços para o atendimento da relação $\mathrm{Mn} / \mathrm{S}$ e outras propriedades do aço GOAT. Por isso, a ocorrência da dessulfuração do aço na panela deve estar sob controle.

O processo de dessulfuração pode ser representado como:

$$
C a O_{(l)}+\underline{S}=C a S_{(l)}+1 / 2 O_{2(g)}
$$

No equilíbrio:

$$
\Delta G^{\circ}=-R T \ln \frac{a_{C a S} \cdot p_{O_{2}}^{1 / 2}}{a_{C a O} \cdot h_{S}}
$$

Analisando a equação [2], vê-se que a dessulfuração é favorecida pelo(a):

- ambiente redutor;

- menor atividade do $\mathrm{CaS}$;

- maior atividade do $\mathrm{CaO}$;

- maior temperatura.

A escória sintética desenvolvida possui fases combinadas quimicamente entre $\mathrm{CaO}, \mathrm{SiO}_{2}$ e $\mathrm{Fe}_{2} \mathrm{O}_{3}$ para a garantia da não dessulfuração na panela permitindo um maior controle do enxofre no aço GOAT. Cálculos termodinâmicos realizados para este processo mostraram que não ocorrerá a dessulfuração se o $\mathrm{CaO}$ estiver quimicamente combinado, ou seja, $\Delta G>$ 0 .

Diferentemente, a cal utilizada como insumo no processo fornece $\mathrm{CaO}$ livre que nas condições do sistema favorecerá o processo de dessulfuração do aço pois neste caso $\Delta G<0$, e. A equação [3] a seguir representa muito bem esta condição: 


$$
\mathrm{CaO}_{(l)}+\underline{S} \rightarrow \mathrm{CaS}_{(l)}+1 / 2 \mathrm{O}_{2(g)}
$$

Portanto, deve ser muito bem controlada a utilização do insumo cal nesta etapa da fabricação do aço dando preferência, se possível para utilização de insumos com $\mathrm{CaO}$ quimicamente combinado atendendo os demais parâmetros de processo como T liquidus, viscosidade, dentre outros para se ter um melhor controle do enxofre do aço e, consequentemente, da relação $\mathrm{Mn} / \mathrm{S}$ e do processo de fabricação do aço GOAT.

\section{2 - Teores finais de alumínio e titânio na composição química final do aço GOAT}

Após implantação do projeto, houve um aumento de $30 \%$ de corridas com atendimento a faixa de alumínio + titânio do produto M3, produto de aplicação mais nobre do GO(Figura 4).

\section{Evolução teores $\mathrm{Al}+\mathrm{Ti}(\%$ Corridas com residual $<20 \mathrm{ppm})$}

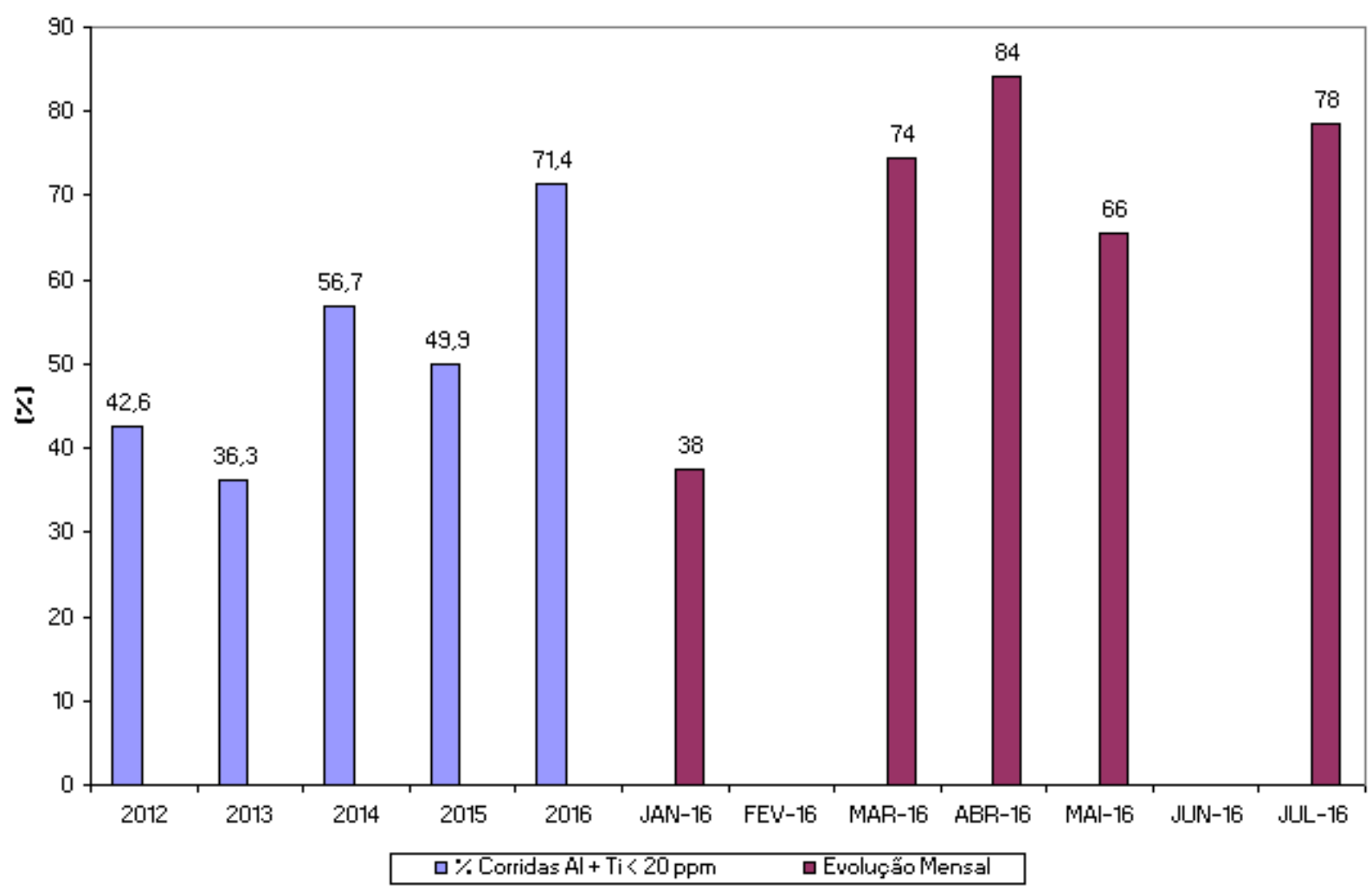

Figura 4 - Evolução dos teores de Al+Ti no aço GO nas corridas com residual menor que 20ppm.

\section{3 - Correção da altura de escória durante processo de aquecimento no Forno} Panela

Com a criação da escória sintética VAMFLUX 4005 a correção da altura de escória no Forno Panela foi possível sem comprometer basicidade binária da escória. Anteriormente a correção da altura era feita somente com a escória sintética VAMFLUX RGO SI, aumentando os valores de basicidade binária, comprometendo a obtenção de baixos teores de alumínio e titânio ao 
final do processo de elaboração. Esta correção com a utilização das duas escórias sintéticas VAMFLUX possibilitou a eliminação do risco de sucateamento do aço GOAT por fora de faixa devido Al+Ti no metal.

\section{4 - Melhoria do atendimento a faixa preferencial do GOAT}

Como consequência direta do melhor controle da basicidade do processo e após ações para adequação da escória na metalurgia secundária do aço GOAT houve melhoria expressiva no índice de atendimento ao produto M3, Figura 5, produto este possuidor de melhores propriedades e de maior valor agregado dentro da classificação de aço GOAT.

Atendimento a faixa otimizada GOAT (M3)

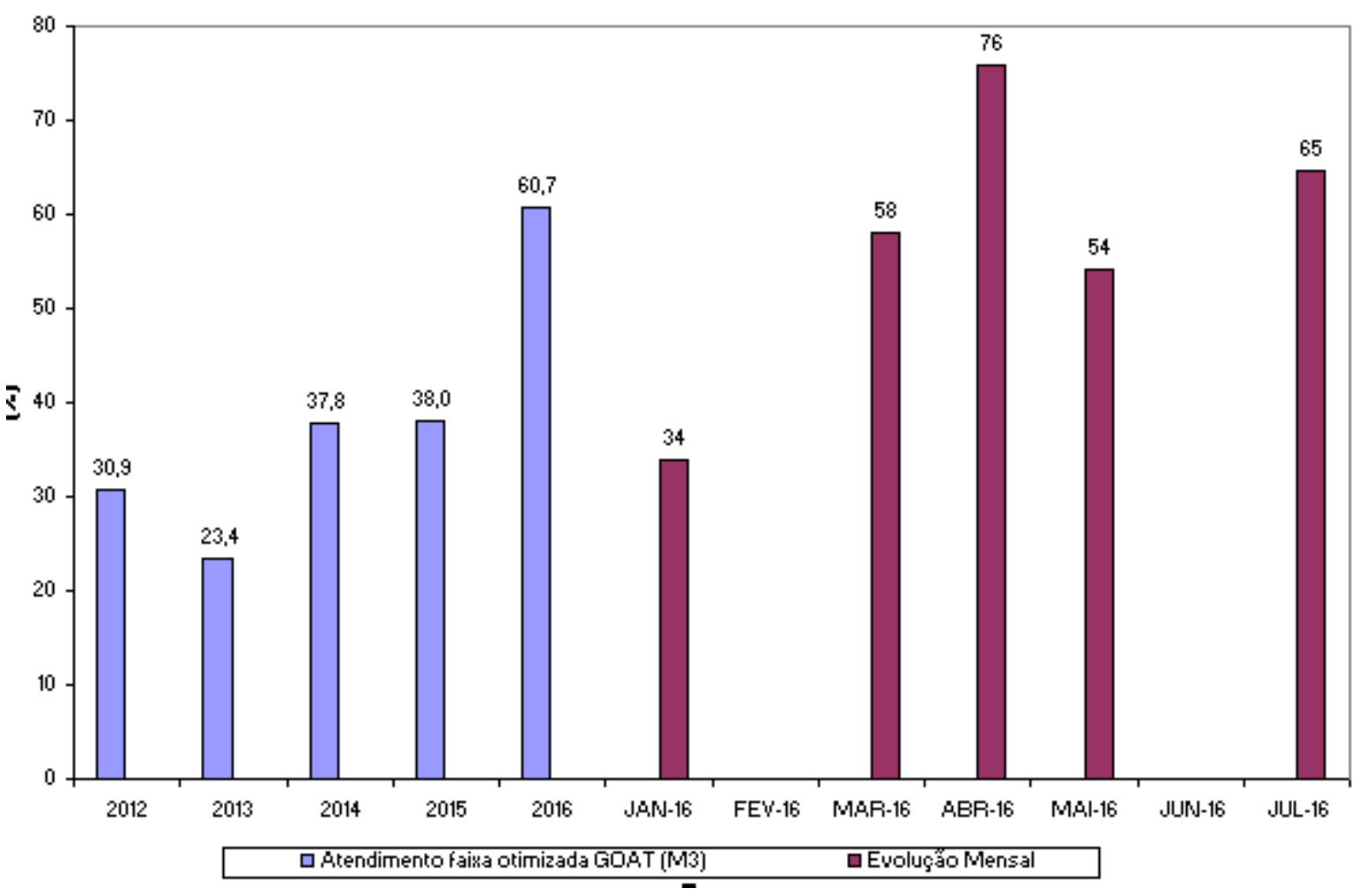

Figura 5 - Percentual de atendimento de composição química do aço para a faixa otimizada(M3).

Em 2017 alguns resultados de M3 de campanhas do GOAT foram superiores a 85\% mostrando que o projeto foi um sucesso e que com maior dominio da técnica e da nova pratica resultados cada vez melhores surgirão.

\section{5 - Basicidade binária da escória final Forno Panela}

Após ações para adequação da escória na metalurgia secundária do aço GOAT, houve estabilização da basicidade binária da escória final do Forno Panela dentro da faixa especificada para o processo. Os resultados mostraram que o uso do VAMFLUX para o ajuste fino da basicidade da escória foi eficaz. 
Variação percentual média da basicidade da escória final Forno Panela

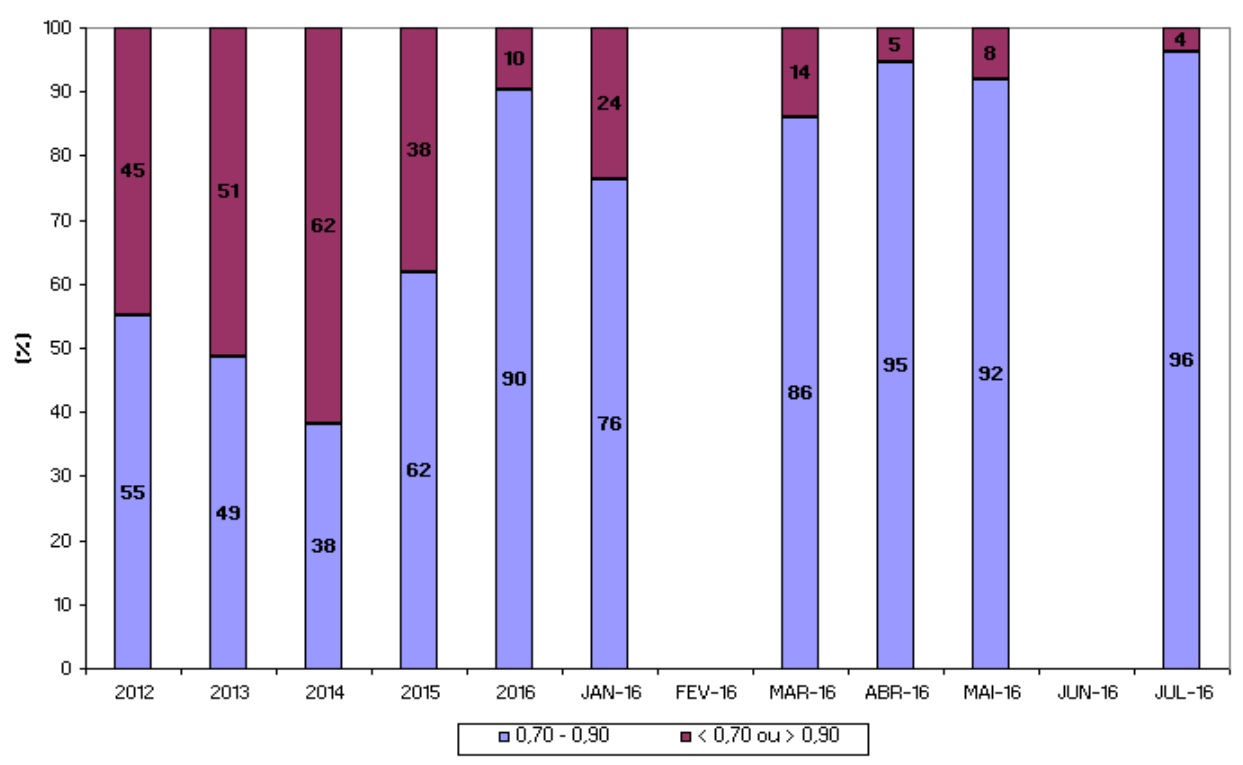

Figura 6 - Variação percentual média da basicidade binária da escória final no forno panela.

\section{6 - Basicidade ternária da escória final no forno panela.}

O ajuste fino da basicidade binária possibilitou o ajuste fino da basicidade ternária da escória na panela. A Figura 8 mostra a variação da basicidade ternária com o percentual de alumínio e titânio no metal em PPM.

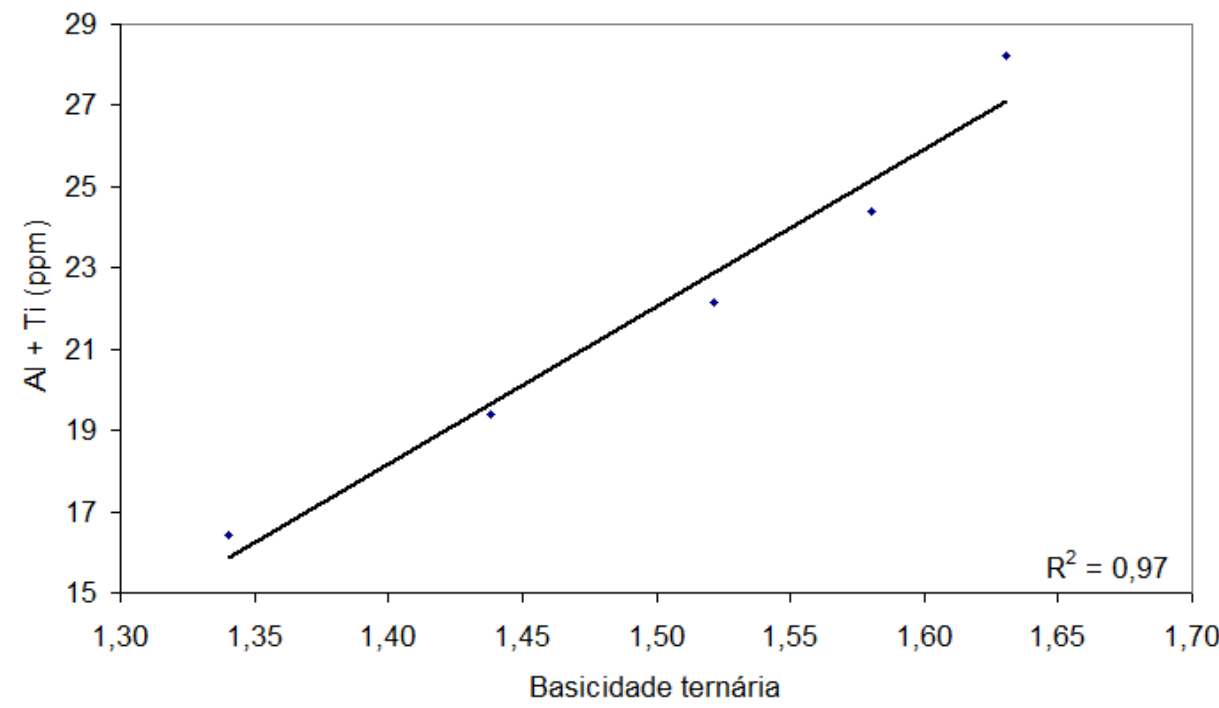

Figura 7 - Variação da basicidade ternária com a quantidade de Al+Ti no aço GOAT na escória final no forno panela.

Pode-se observar que existe uma forte correlação entre estas variáveis. Por isso, é muito importante que a basicidade ternária, que leva em conta a participação do componente MgO, seja também considerada na análise da escória na produção do aço GO uma vez que o teor de de $\mathrm{MgO}$ na escória é representativo e sua influência na viscosidade e temperatura liquidus é relevante. Como a escória tem contato direto com os refratário da sua linha (dolomíticos), o 
ajuste da basicidade binária e ternária contribuíram fortemente para a redução do desgaste do refratário da panela na metalurgia secundária.

\section{7 - Redução do risco de sucateamento por fora de faixa em Alumino + Titânio}

Após ações para adequação da escória na metalurgia secundária do aço GOAT, não houve corridas sucatadas ou retornadas para o convertedor por fora de faixa em alumínio e titânio. A Figura 8 mostra que ocorria uma perda de aço que representou nos últimos 4 anos um prejuízo de $R \$ 1,2$ milhão antes da adequação da escória da metalurgia secundária com o uso do VAMFLUX combinado às novas práticas operacionais. (Base controladoria Set/2016: Custo sucata mento LC $R \$ 927,19 / t$; Custo retorno corrida para convertedor $R \$ 215,00 / t)$.

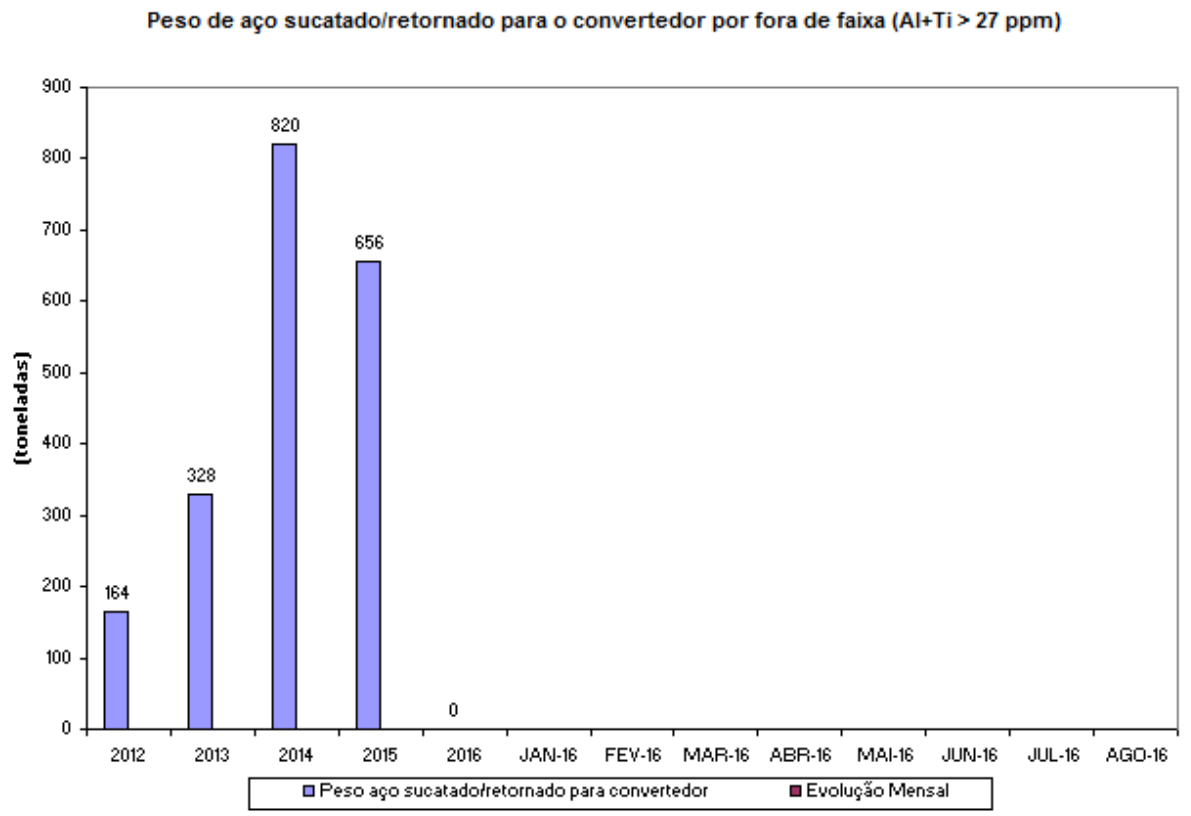

Figura 8 - Redução a zero do risco de sucateamento de aço GOAT devido teores de Al+Ti fora de faixa especificada.

\section{4 - CONCLUSÀO}

Com o desenvolvimento e implementação do projeto, que teve forte participação da equipe da aciaria e do fornecedor da escória sintética o controle da escória no Forno Panela ficou mais efetivo e possibilitou:

- Redução dos teores finais de alumínio e titânio ao final do processo de elaboração no Forno Panela.

- Possibilidade de correção da quantidade de escória para aquecimento no Forno Panela sem comprometer a basicidade de escória requerida no processo.

- Aumento do atendimento a faixa otimizada do aço GOAT (M3) de 33\% para 65\%(até 2016).

- Redução do desgaste de panelas na elaboração do aço GOAT na metalurgia secundária. 
- Redução do risco de sucatamento por fora de faixa em alumínio e titânio do aço GOAT na Aciaria, que representou uma perda nos últimos 4 anos superior a $R \$ 1,2$ milhão.

- Estabilização da basicidade binária da escória final do Forno Panela dentro da faixa desejável.

\section{5 - AGRADECIMENTOS}

- À APERAM pela confiança e apoio ao trabalho.

- Ao Prof. Dr. Luiz Fernando Andrade de Castro do Departamento de Engenharia Metalúrgica e Materiais da UFMG orientador do mestrado.

- Ao Dr. Pedro Nolasco, Gerente Técnico do CPDI - Centro de Pesquisa, Desenvolvimento e Inovação do Grupo VAMTEC e sua equipe pelo apoio ao trabalho.

- Este trabalho foi parcialmente financiado pela Coordenação de Aperfeiçoamento de Pessoal de Nível Superior (CAPES/PROEX), Brasília, DF, Brasil; e Pró-Reitoria de Pesquisa da Universidade Federal de Minas Gerais, Belo Horizonte, MG, Brasil.

\section{6 - REFERÊNCIAS BIBLIOGRÁFICAS}

(1) NOLASCO-SOBRINHO, P.J. e TENORIO, J.A.S. Influência da basicidade da escória na redução do óxido de cromo presente em poeiras geradas na produção de aço inoxidável. SEMINÁRIO DE FUSÃO, REFINO E SOLIDIFICAÇÃO, 36. ABM, ES, 2005.

(2) CAMPOS, A.A.;QUINTÃO, H.A.; CASTRO, LFA.; NOLASCO-SOBRINHO, P.J.; OLIVEIRA, S.P. Desenvolvimento de escória sintética sinterizada para a produção de aços elétricos de grão orientado(GO). SEMINÁRIO DE ACIARIA INTERNACIONAL, 41. ABM, RJ, 2010.

(3) NOLASCO-SOBRINHO, P.J.; QUINTÃO, H.A.; VIEIRA, C.B.; ASSIS, P.S. et alli. Desenvolvimento de escória sintética para fabricação de aço silício grão orientado(GO) na aciaria da ACESITA. SEMINÁRIO DE FUSÃO, REFINO E SOLIDIFICAÇÃO, 31. ABM, ES, 2005.

(4) NOLASCO-SOBRINHO, P.J.; LIMA, J.A.; VIEIRA, C.B.; ASSIS, P.S. Fundamentos para a fabricação de escória sintética utilizada no tratamento de aço no forno panela. SEMINÁRIO DE FUSÃO, REFINO E SOLIDIFICAÇÃO, 31. ABM, ES, 2005.

(5) ANDRADE, P.R.C; FERNANDES, W.M.A; LANA,N.O.A. Fabricação de aços ao silício de grão orientado na Acesita. Metalurgia da ABM. Vol.45, n. 375, p.126-129. 1989.

(6) RIBEIRO, D.B.; QUINTÃO, H.A. et. alli. REFINO SECUNDÁRIO DOS AÇOS. Curso da ABM. 206p.

(7) BARRIOS, S.R.; COSTA, E.A Interação físico-química de escórias sintéticas com o refratário de panelas de aço. SEMINÁRIO DE FUSÃO, REFINO E SOLIDIFICAÇÃO, 25. ABM, RS, p. 253, 1993.

(8) BARRIOS, S.R. et al. Considerações metalúrgicas a respeito da utilização de escórias sintéticas em forno panela. SEMINÁRIO DE FUSÃO, REFINO E SOLIDIFICAÇÃO, 26. ABM, BA, p. 287, 1994. 
(9) ENGH, T.A. Principles of Metal Refining. Cap. 6: Stainless Steelmaking in Converter, p. 281-301. Oxford University Press: New York. 1992.

(10) SLAG ATLAS. $2^{\text {nd }}$ Edition. Verlag Stahleisen GmbH. Düsseldorf. Germany.1995. 